\title{
A SNP in intron 8 of CD46 causes a novel transcript associated with mastitis in Holsteins
}

\author{
Xiuge Wang ${ }^{1 \dagger}$, Jifeng Zhong ${ }^{1 \dagger}$, Yundong Gao ${ }^{1 \dagger}$, Zhihua Ju and Jinming Huang ${ }^{1,2^{*}}$
}

\begin{abstract}
Background: The membrane protein CD46, a ubiquitous cell surface pathogen receptor, can bind Streptococcus to trigger cell autophagy, which is a critical step in the control of infection.

Results: In this study, we found a new splice variant designated CD46 transcript variant (CD46-TV). The splice variant is characterized by the retention of a 48 bp sequence from intron 8 of the bovine CD46 gene, which encodes a putative protein enlarged by 16 amino acids. CD46-TV mRNA was found to be over expressed in mastitis-infected mammary gland tissues relative to healthy tissues. A single nucleotide polymorphism (c. $1033+2184 \mathrm{C}>\mathrm{T})$ in the exonic splicing enhancer (ESE) motif region was shown to result in the CD46-TV aberrant splice variant through constructing alternative alleles using the PSPL3 exon capturing vector and transfecting these into $293 \mathrm{~T}$ cells. Allelic frequency in 56,682 individuals belonging to 112 Bos taurus, Bos indicus, Bos javanicus, Bos grunniens and Bos mutus, etc. suggests that the $C$ allele (80.09\%) is the ancestral allele. Association analysis found that the mean genomic estimated breeding values (gEBV) for milk somatic cell score and the occurrence of clinical mastitis, as well as the milk somatic cell score of Chinese Holsteins with the CT genotype was lower than those of individuals with either the $\mathrm{CC}$ or $\Pi$ genotypes. The mean gEBV for udder health synthesis for the $\Pi$ genotype was greater than those for the CC or CT genotypes.

Conclusions: Our findings suggest that the CD46 gene likely plays a critical role in the risk of mastitis caused by Streptococcus in dairy cows via an alternative splicing mechanism caused by a functional mutation in intron 8 . Our data also underline the importance of variation within ESEs in regulating transcript processing.
\end{abstract}

Keywords: CD46, Alternative splicing, Functional SNP, Cattle, Mini-gene system

\section{Background}

The selection of susceptibility-related genes is considered to be one of the best long-term means to improve resistance to mastitis in dairy cattle and may reduce drug use, improve milk quality and safety, and reduce economic loss [1,2]. As a prominent mechanism for posttranscriptional regulation, alternative splicing is significant in cell development, differentiation, physiological functions and pathogenesis, and it has been reported to have many critical roles in mammalian diseases including bovine mastitis [3-7]. Many studies have

\footnotetext{
* Correspondence: huangjinm@sina.com

${ }^{\dagger}$ Equal contributors

'Dairy Cattle Research Center, Shandong Academy of Agricultural Sciences, No.159 North of Industry Road, Jinan, Shandong 250131, China

${ }^{2}$ Division of Animal Sciences, University of Missouri, Columbia, MO 65211,
} USA

\section{Ciomed Central}

shown that alternative splicing is also closely related to immune function [8-10].

Pre-mRNA splicing involves a large molecular complex called the spliceosome that consists of four small nuclear ribonucleoprotein particles (U1, U2, U4/U6 and U5 snRNPs) and other non-snRNP splicing factors, such as serine/arginine rich (SR) and U2AF proteins [11]. The exons of vertebrate genes are generally separated by large introns, and possess 5 ' splice sites, branch points, pyrimidine tracts and 3' splice sites which are very short conserved elements that are required for constitutive splicing [12]. The splicing of alterative exons is also modulated by cis-acting elements, such as positive exon splicing enhancers (ESEs) which regulate the gene splicing process by interacting with SR proteins. Through binding to an ESE, SR proteins can enhance U1 snRNP binding to a 5' splice site resulting in a splicing reaction, and can also promote $\mathrm{U} 2 \mathrm{AF}$ recruitment to the pyrimidine 
tract, which leads to the activation of the adjacent 3' splice site $[13,14]$. As has previously been shown, mutations in ESEs result in aberrantly spliced transcripts, and may cause human diseases by affecting the encoded protein $[15,16]$.

CD46 is a single stranded transmembrane glycoprotein which anchors to almost all nucleated cells, including granulocytes, platelets, T cells, B cells, NK cells, fibroblast cells, skin cells, endothelial cells and stellate glial cells. CD46 protein is composed of a region comprising four structurally related short consensus repeats (SCRs), a serine, threonine and proline-rich (STP) region, a short region of unknown function, a hydrophobic transmembrane domain (TM) and a cytoplasmic tail (cyt). The STP region is variable, and encoded by three exons $(\mathrm{A}, \mathrm{B}, \mathrm{C})$ which are commonly expressed as $\mathrm{B}+\mathrm{C}$ or $\mathrm{C}$ isoforms. One of two non-homologous alternative cytoplasmic tails (cyt-1 or cyt-2) resulting from alternative splicing contains signaling motifs which drive the differential processing of isoforms $[17,18]$. CD46 belongs to the family of regulators of complement activation, and cleaves complement factors $\mathrm{C} 3 \mathrm{~b}$ and $\mathrm{C} 4 \mathrm{~b}$ to protect normal cells from complement-mediated damage $[19,20]$. CD46 can also be used as a costimulatory molecule involved in $\mathrm{T}$ cell activation through altering cell polarity and preventing normal cell responses to antigen presentation [21-23]. There are reports which show that pathogen receptor CD46 on the cell surface can trigger cell autophagy to control infection by Streptococcus $[17,24]$. Bovine mastitis is the inflammation of the mammary gland caused primarily by bacteria, such as Staphylococcus aureus, Streptococcus, and Escherichia coli. Therefore, we speculated that the CD46 gene likely plays a role in the defense of dairy cattle to Streptococcus induced mastitis by an alternative splicing mechanism caused by a functional mutation which causes an aberrant transcript.

We found that a SNP in intron 8 of the bovine CD46 gene causes the partial retention of intron 8 sequences within mature CD46 RNAs. By cloning alternative CD46 partial alleles into a minigene expression system which was transfected and expressed in 293 T cells, we demonstrate that this mutation disrupts an ESE, and causes the production of an aberrant CD46-TV isoform. Association analysis between four udder health traits of Holsteins and their CD46 SNP (c. $1033+2184 \mathrm{C}>\mathrm{T}$ ) genotypes suggests that this SNP may be a useful functional marker for molecular breeding for mastitis-resistance in dairy cows.

\section{Results}

The novel splice variant CD46-TV was identified in mammary gland tissues

Specific CD46F and CD46R primers were used to amplify the 5' untranslated region (5'UTR) to the 3' untranslated region (3'UTR) of the bovine CD46 gene (Figure 1A) from the 4 pooled cDNA composed of 16 mammary tissue samples. PCR conditions for annealing were designed using 12 temperature gradients between $52^{\circ} \mathrm{C}$ and $65^{\circ} \mathrm{C}$. In addition to the expected smaller $2005 \mathrm{bp} \mathrm{PCR} \mathrm{product,}$ a larger band was also detected by electrophoresis on $2 \%$ agarose gel from the products produced at increased annealing temperatures (see Additional file 1: Figure S1), indicating that an aberrant splice variant might exist.

To confirm the putative bovine CD46 splice variant, we purified and cloned the largest PCR product. A total of 30 clones were sequenced individually, and we identified the new splice variant, named as CD46-TV (GenBank accession number: KM114056), from 6 clones. Compared to the CD46-complete transcript, BLAST analysis indicated that the splice variant $C D 46-T V$ retained a 48 bp sequence from intron 8 (Figure 1B).

\section{A putative functional SNP in intron 8 of CD46}

To identify the molecular cause of the aberrant CD46- $T \mathrm{~V}$ splice variant, primers CD46F1 and CD46R1 were designed to amplify the adjacent region of intron 8 (Figure 1B). SNP (c. $1033+2184 \mathrm{C}>\mathrm{T}$ ) was found by sequencing the PCR amplification products from dairy cow DNA, and is located in the 48 bp sequence retained in the CD46- $T V$ transcript (Figure 1B).

ESEfinder 3.0 (http://rulai.cshl.edu/cgi-bin/tools/ESE3/ esefinder.cgi?process=home) [25] software was used to predict whether the SNP affected the production of the new transcript CD46-TV. ESEfinder predicted the SNP to be located within overlapping ESE motifs for SR proteins, and that the introduction of the c. $1033+2184 \mathrm{C}>\mathrm{T}$ mutation abolished two binding sites for the splicing factors SRSF2 (SC35) and SRSF5 (SRp40) (Figure 2). These analyses suggest that there should be a correlation between the SNP alleles and the presence or absence of the splice variant $C D 46-T V$.

\section{The C allele of SNP (c. $1033+2184$ C > T) is identified as the ancestral allele}

Genotyping indicated that the $\mathrm{C}$ allele was more frequent in the sample of 230 Chinese Holstein cows (Table 1). To determinate which allele is the mutant, allele frequency was further investigated in diverged bovid species. Interestingly, the SNP (c. $1033+2184 \mathrm{C}>\mathrm{T}$ ) is located on the Illumina BovineSNP50K Beadchip (SNP name: Hapmap48320-BTA-40139; rs ID: 41634826), thus we extracted genotype data for this SNP and estimated allele frequency in 56,682 individuals belonging to 112 breeds or species including Bos taurus, Bos indicus, Bos javanicus, Bos grunniens and Bos mutus (see Additional file 2: Table S1). Within Bos taurus breeds (e.g., Angus, Charolais, Hereford, Holstein, Jersey, Limousin and Simmental) the frequency of the T-allele was 0.2042 to 


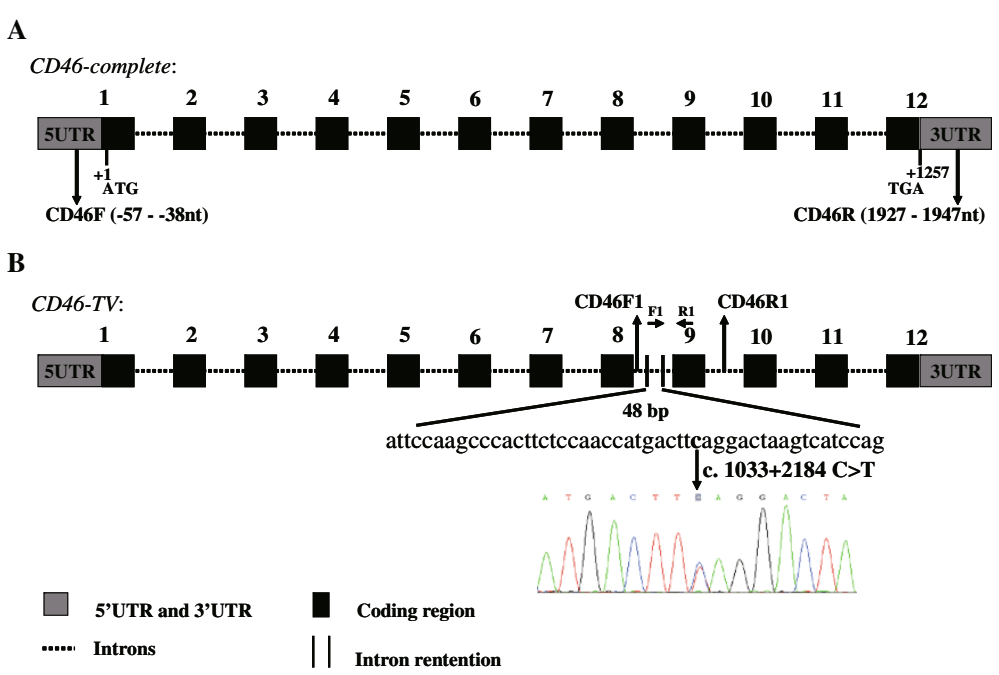

Figure 1 Identification of a novel CD46 splice variant. (A) Genomic structure of the bovine CD46 gene. CD46 gene consists of 12 exons, comprising 1257 bp of coding sequence. The positions of the primers (CD46F, CD46R) used in the CD46 cloning experiment are indicated by black arrows. (B) The splicing pattern of the CD46-TV splice variant. The CD46-TV (GenBank accession number: KM114056) transcript retains a 48 bp sequence from intron 8 . The F1 and R1 primers are located within the 48 bp retained intron sequence and exon 9, respectively. The position of the A nucleotide in the start codon (ATG) is defined as +1 .

0.3495 , while the T-allele was nearly absent in 12 other Bos species (see Additional file 2: Table S1) suggesting that $\mathrm{C}$ is the ancestral allele and $\mathrm{T}$ is the mutant.

\section{Mutation in the putative ESE generates the novel splice transcript}

To determine whether the c. $1033+2184 \mathrm{C}>\mathrm{T}$ nucleotide substitution in intron 8 leads to the abrogation of the predicted SR protein motifs and causes aberrant splicing, we respectively amplified 1421 bp genomic fragments spanning 914 bp of intron 8, 54 bp of exon 9 and $453 \mathrm{bp}$ of intron 9 alternatively harboring the c. $1033+2184$ C-allele and c. $1033+2184$ T-allele and cloned the two fragments into the pSPL3 vector (Figure 3A).

After transfecting the two minigene plasmids into $293 \mathrm{~T}$ cells, mRNAs were isolated at $24 \mathrm{~h}$ following transfection,

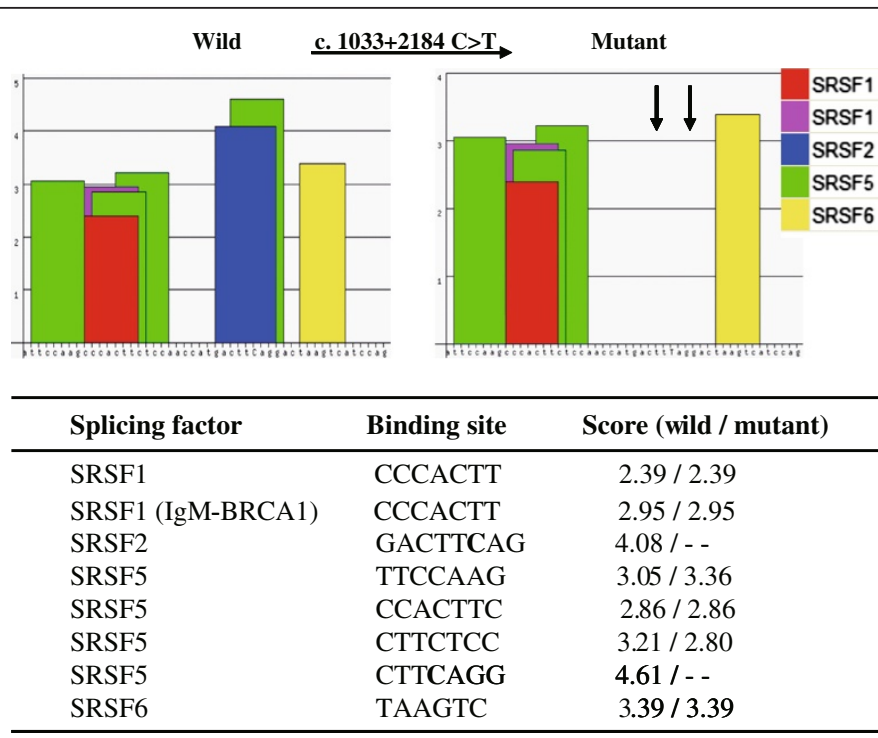

Figure 2 Exonic splice enhancer (ESE) motif threshold scores associated with CD46 genotypes. Bar graphs represent scores above the threshold for the ESE motifs within the ancestral (wild) and mutant haplotypes. The arrows indicates that the signal for the SRSF2 and SRSF5 motifs disappear when the mutation (c. $1033+2184$ C > T) is introduced into the wild-type sequence. Wild type (C) sequence: attccaagcccacttctccaaccatgacttcaggactaagtcatccag; Mutant type (T) sequence: attccaagcccacttctccaaccatgactttaggactaagtcatccag. 
Table 1 Association analysis between different genotypes and somatic cell score in $\mathbf{2 3 0}$ Chinese Holstein cows

\begin{tabular}{ccccc}
\hline Genotype & $\begin{array}{c}\text { Sample } \\
\text { number }\end{array}$ & $\begin{array}{c}\text { Genotype } \\
\text { frequencies }\end{array}$ & $\begin{array}{c}\text { Allele } \\
\text { frequencies }\end{array}$ & $\begin{array}{c}\text { Somatic } \\
\text { cell score }\end{array}$ \\
\hline $\mathrm{CC}$ & 102 & 0.44 & $0.71(\mathrm{C})$ & $4.91 \pm 0.33^{\mathrm{a}}$ \\
$\mathrm{CT}$ & 124 & 0.54 & & $3.84 \pm 0.35^{\mathrm{b}}$ \\
$\Pi \mathrm{T}$ & 4 & 0.02 & $0.29(\mathrm{~T})$ & $4.97 \pm 0.45^{\mathrm{a}}$ \\
\hline
\end{tabular}

Superscript different letters $(a, b)$ in the same column denote difference $p<0.05$.

reverse transcribed and RT-PCR was applied to detect the CD46 splicing pattern with vector-specific primers (SD6 and SA2). The wild-type and mutant-type constructs all gave rise to a $317 \mathrm{bp}$ PCR fragment, and the empty pSPL3 control a 263 bp PCR product. However, the plasmid construct with the wild-type c. $1033+2184$ C-allele also yielded two length of RT-PCR product. One is a larger RT-PCR product and the other is the $317 \mathrm{bp}$ PCR band (Figure 3B). Through subsequent cloning experiment, we confirmed that the size of the larger band was $365 \mathrm{bp}$.
We also genotyped sixteen Chinese Holstein cows including $9 \mathrm{CC}, 5 \mathrm{CT}$ and 2 TT genotype individuals. Through RT-PCR experiment using F1 and R1 primers, the $C D 46-T V$ transcript was found to only be expressed in the mammary glands of cows possessing $C$ allele. Further, the expression level of the CD46-TV transcript was relatively higher in cows with the $\mathrm{CC}$ than the CT genotype (see Additional file 1: Figure S2).

\section{The SR protein and ESE functions in the alternative splicing of CD46}

Within the Metazoa, almost all of the pre-mRNA produced within the cell nucleus have GU bases in the 5 ' splice site of adjacent introns and AG bases in the 3 ' splice site, which is recognized as the GU-AG rule or Chambon rule [26]. To ascertain the reason for the retention of $48 \mathrm{bp}$ of intron 8 sequence within the CD46-TV transcript, we analyzed the $48 \mathrm{bp}$ sequence and the intronic splicing site bases, and found that the splicing

A

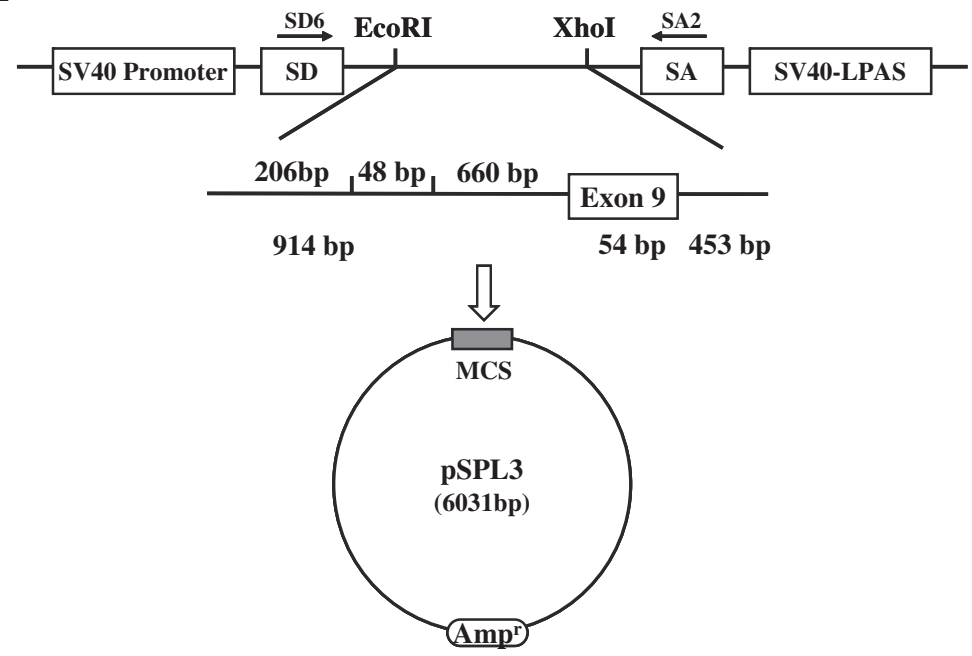

B

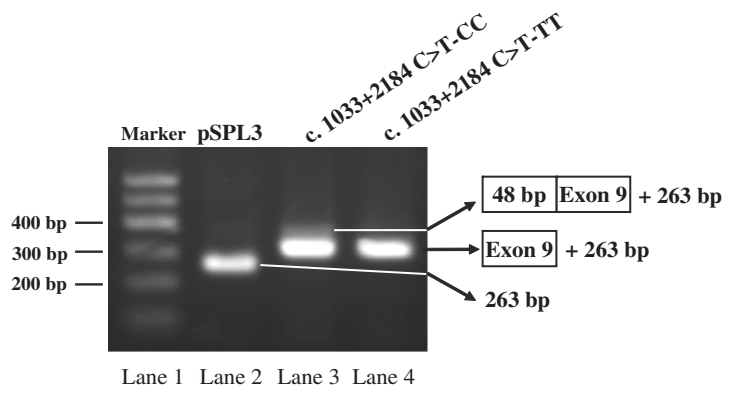

Figure 3 The exon trapping vector pSPL3 used to assay SNP function. (A) The PSPL3 vector contains SD (splice donor) and SA (splice acceptor) sites that operate as exons, and a functional intron, with transcription beginning following the SV40 promoter and ending at the LPAS (late poly (A) signal). Wild PSPL3-W and mutant pSPL3-M plasimds containing 914 bp of intron 8, exon 9 and 453 bp of intron 9 and harboring either the C or T alleles were separately cloned into the ECoRI and Xhol cloning sites of the PSPL3 vector. (B) Agarose gel electrophoresis of RT-PCR products. SD6 and SA2 primers were designed for RT-PCR amplification of cDNA sequences generated by transfected 293 T cells. Lane1: Marker;DNA Marker 600 (TIANGEN, China); Lane2: 263 bp; Lane3: 365 bp (263 bp + 54 bp + 48 bp) and 317 bp (263 bp + 54 bp); Lane 4: 317 bp (263 bp + 54 bp). MCS: multiple cloning sites. 
site bases conformed with the GU-AG rule, while the c. $1033+2184 \mathrm{C}>\mathrm{T}$ mutation disrupted two ESE motifs recognized by the SRSF2 and SRSF5 proteins (Figure 4). We therefore infer that the presence of the SNP $T$ allele eliminates the production of the CD46-TV splice variant.

\section{Analysis of CD46-TV mRNA and peptide sequences}

The identity of the bovine CD46, CD46-TV and other species (pig, dog, mouse, monkey and human) mRNA and peptide sequences is shown in Additional file 1: Figure S3 and Figure S4. A BLAST comparison of sequences from different species revealed that the bovine CD46 amino acid sequence (NCBI: NP_001229490.1) had a 59\% identity with porcine CD46 (NCBI: NP_999053.1), 48\% with human' (NCBI: NP_002380.3) and 36\% with mouse' (NCBI: NP_034908.1) for the open reading frame shifting (see Additional file 1: Figure S3). From the analysis of the porcine CD46 amino acid, the sequences for the four SCR regions were identical. However, the STP, TM and cyt domains differed between the two species. Moreover, we found that the 16 amino acids translated from the $48 \mathrm{bp}$ incorporated intronic sequence within the CD46- $T V$ transcript were located in the STP region and were highly conserved with the porcine STP region (Figure 5 and see Additional file 1: Figure S3 and Figure S4).

\section{Expression of the CD46-TV splice variant in cow mammary gland tissues}

To understand the relationship between the CD46-TV transcript and dairy cow mastitis, the relative quantification of the transcript in mammary glands was performed by RT-qPCR from three healthy and three Streptococcus infected and mastitic dairy cows with the $\mathrm{CC}$ genotype. The mastitis-infected tissues revealed a relatively higher $C D 46-T V$ mRNA expression compared with healthy tissues $(\mathrm{p}<0.05$, Figure 6$)$, indicating that the $\mathrm{C}$ allele would be associated with a reduced risk of mastitis.

\section{Relationship between genotypes of the SNP} (c. $1033+2184 \mathrm{C}>\mathrm{T}$ ) and milk somatic cell score, as well as gEBV of STMA, CEL and MACL of Holsteins

Somatic cell count is considered to be an indicator for dairy mastitis [27] and it is often converted into somatic cell score (SCS) due to the skewness of the somatic cell count distribution [28]. To investigate whether the SNP was associated with mastitis in dairy cows, we first used the CD46F1 and CD46F1 primers to genotype 230 cows by direct sequencing, and the association analysis was performed between genotype and somatic cell score in these Chinese Holstein cows. The results revealed that the estimated frequencies of the $\mathrm{C}$ and $\mathrm{T}$ alleles were $71 \%$ and $29 \%$, respectively. Moreover, cows with the $\mathrm{CC}$ and TT genotypes showed a relative higher SCS than individuals with the CT genotype $(p<0.05$, Table 1).

CEL is the genomic breeding value of somatic cell score. MACL is an index used to evaluate the occurrence of clinical mastitis. gEBV for STMA is a combination of somatic cell score and clinical mastitis (http:// idele.fr/fileadmin/medias/Documents/INTRO_PH_141_va. pdf). A high breeding value means a high occurrence of mastitis. In experiment four, to investigate whether this SNP was associated with mastitis in Holsteins, we analyzed the association between genotypes and mastitis-related traits in 98 Chinese Holsteins with gEBVs. The estimated frequencies of the $\mathrm{C}$ - and $\mathrm{T}$ alleles were $83.16 \%$ and $16.84 \%$, respectively. Moreover, cows with the CC and TT genotypes showed a relative higher STMA and CEL than individuals with the CT genotype $(p<0.05$, Table 2$)$. The result suggests that there is some kind of heterozygote advantage although the mechanism by which this occurs is really not clear. Moreover, the gEBV of MACL of the Holstein with the $\mathrm{CC}$ or $\mathrm{CT}$ genotypes was significantly lower than for the TT genotype (Table 2). These results suggest that the $\mathrm{CC}$ and $\mathrm{CT}$ genotypes are advantageous for bovine mastitis resistance and we conclude that the c. $1033+2184 \mathrm{C}>\mathrm{T}$ mutation affects cow mastitisresistance.

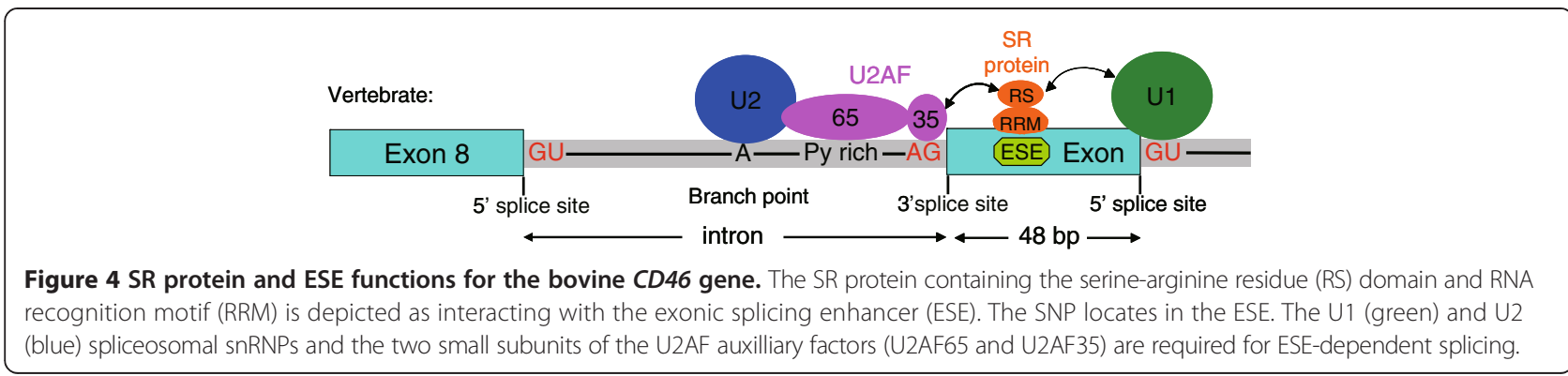




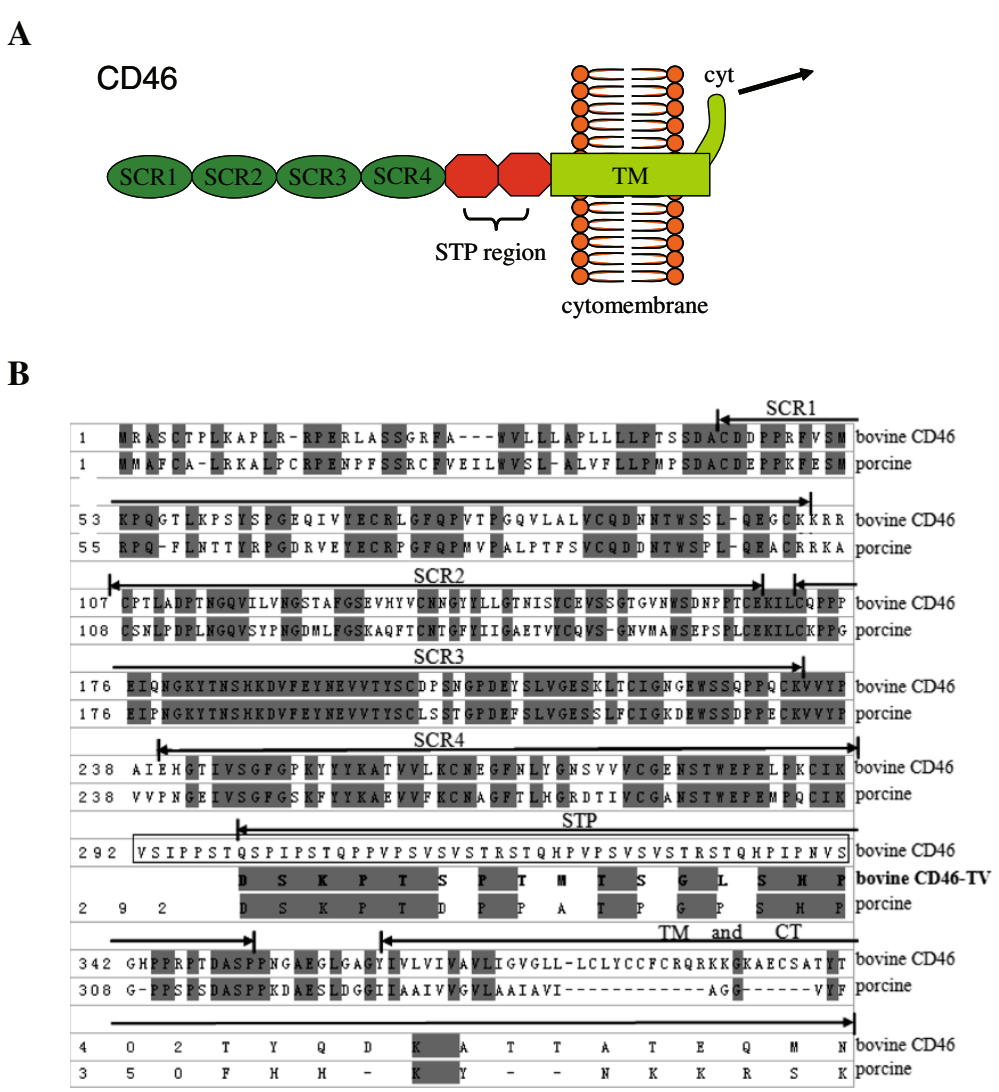

Figure 5 Analysis of the CD46 and CD46-TV transcripts. (A) Diagram of CD46 structure. The CD46 protein contains four short consensus repeats (SCRS), and a serine, threonine and proline-rich (STP) region that is followed by a short region of unknown function, a transmembrane domain (TM) and a cytoplasmic domain (cyt). The arrow indicates the signaling path after accepting the ligand. (B) Comparison of the bovine and porcine CD46 amino acid sequences. The bovine CD46 amino acid sequence (NCBI: NP_001229490.1) was aligned to the porcine sequence (NCBI: NP_999053.1) by BLAST. Identical amino acid residues within the two species are indicated in grey. The positions of the SCRs, STP, TM and CT (cyt) domains corresponding to different amino acids are shown above the sequences. Amino acids of the CD46-TV retention transcript in comparison to the porcine CD46 are bolded.

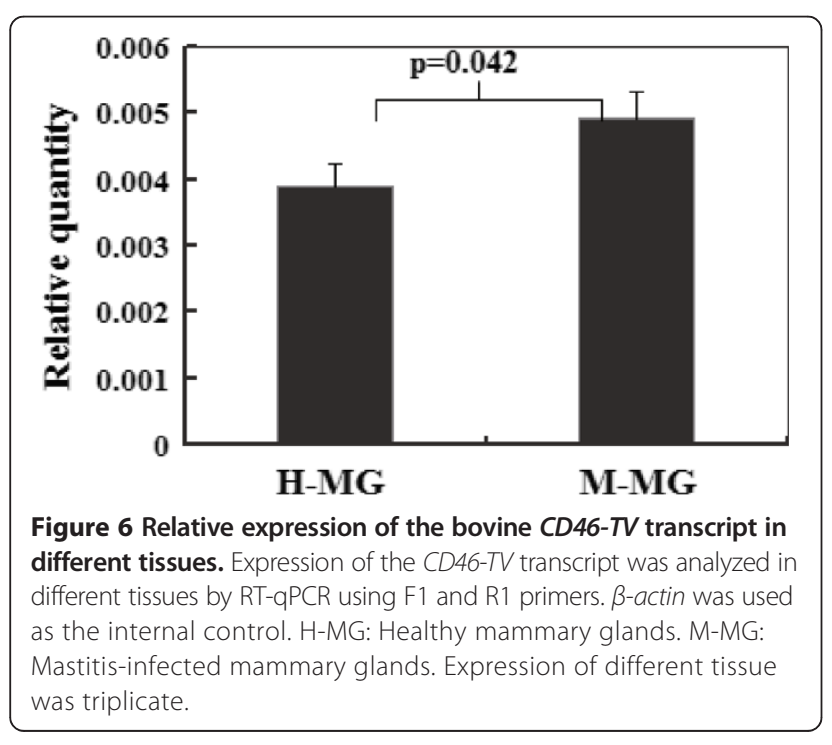

\section{Discussion}

In this study, a new CD46 transcript variant named CD46- $T V$ was identified following the cloning of $C D 46$ mRNA. By sequencing, we identified the SNP (c. $1033+$ $2184 \mathrm{C}>\mathrm{T}$ ) within the retained $48 \mathrm{bp}$ intron 8 sequence of CD46. Using the ESEfinder 3.0 bioinformatics tool, we predicted that this SNP was located within an exonic splice enhancer (ESE) motif, and that the derived Tallele eliminated two potential SR protein binding sites for the splicing factors SRSF2 and SRSF5. The SR proteins are highly conserved in metazoans, are required for constitutive splicing and can influence the regulation of alternative splicing. SR proteins function in the recognition of ESEs and lead to the activation of suboptimal adjacent 5' and 3' splice sites [14], and the SRSF2 (SC35) protein is responsible for the aberrant splicing of premRNAs when increased numbers of binding sites result in the retention of intron and exon skipping [6,29]. It has also been reported that the over-expression of SRSF5 (SRp40) affects the alternative splicing of CD44 [30]. 
Table 2 Genetic effect of SNP (c. $1033+2184$ C > T) on gEBV of STMA, CEL and MACL traits in Holsteins

\begin{tabular}{ccccccc}
\hline Genotype & Sample number & Genotype frequencies & Allele frequencies & STMA gEBV & CEL gEBV & MACL gEBV \\
\hline CC & 68 & 0.69 & $0.8316(\mathrm{C})$ & $0.1279^{\mathrm{a}}$ & $0.2580^{\mathrm{a}}$ & $-0.087^{\mathrm{C}}$ \\
$\mathrm{CT}$ & 27 & 0.28 & & $-0.0037^{\mathrm{b}}$ & $0.1630^{\mathrm{b}}$ & $-0.2500^{\mathrm{b}}$ \\
$\pi$ & 3 & 0.03 & $0.1684(\mathrm{~T})$ & $0.2330^{\mathrm{a}}$ & $0.2333^{\mathrm{a}}$ & $0.2^{\mathrm{a}}$ \\
\hline
\end{tabular}

gEBV - Genomic estimated breeding value; STMA - Udder health synthesis; CEL - Milk somatic cell score; MACL - Occurrence of clinical mastitis;

Superscript different letters $(\mathrm{a}, \mathrm{b}, \mathrm{c})$ in the same column denote difference $p<0.05$.

Therefore, the deletion of the two splicing factors may partially affect splicing which produced a product which retains the $48 \mathrm{bp}$ intronic sequence.

To verify whether the c. $1033+2184 \mathrm{C}>\mathrm{T}$ mutation influenced the aberrant splicing of $C D 46$, we introduced alternative alleles into the pSPL3 exon trapping vector and found that the pSPL3 construct vector with the $\mathrm{C}$-allele permitted the retention of the 48 bp intron 8 sequence while the T-allele construct did not permit this retention. Alternative and constitutive splicing are closely connected and utilize the same splicing mechanism, because components of constitutive splicing are also essential for alternative splicing. Moreover, alternative exons often have suboptimal splice sites or sequence elements compared with constitutive exons, and different activities or amounts of splicing factors in different cell types or developmental stages can also affect the splicing reaction [11]. We analyzed the splicing position sequences producing the CD46-TV transcript, and found that the retained 48 bp sequence conformed to the conditions of an alternative exon and had the potential for alternative splicing. These results suggest that the disruption of the predicted SRSF2 and SRSF5 binding sites caused by the c. $1033+$ $2184 \mathrm{C}>\mathrm{T}$ mutation leads to the retention of the $48 \mathrm{bp}$ intron 8 sequence. CD46 regulates complement activation by binding the $\mathrm{C} 3 \mathrm{~b}$ and $\mathrm{C} 4 \mathrm{~b}$ complement products deposited on host cell membranes and serves as a cofactor for their proteolytic inactivation by the plasma serine protease factor I. This process, which irreversibly prevents C3 and C5 convertase formation, protects host cells from lysis by autologous complementation [19]. The reference CD46complete protein and the putative CD46-TV protein share common SCR1-4 domains containing binding sites for $\mathrm{C} 3 \mathrm{~b}$ and C4b. Therefore, the two CD46 isoforms can play the same role in complement regulation. The mutation is predicted to increase the size of the CD46 protein by 16 amino acids. By BLAST analysis, we found that these 16 amino acids were highly conserved with the STP region of the porcine CD46 protein. The CD46 STP domain serves as a functional modulator of CD46 by altering complement regulatory activity [31]. The STP domain is also crucial for the efficient adhesion of bacteria to host cells [32,33]. Recognition of microbial pathogens is an essential element for the initiation of innate immune responses such as inflammation. The complement regulatory protein
CD46 is used as a cell receptor and can bind with bacteria including Streptococcus pyogenes [34]. Therefore, CD46-TV may play an important role in resistance to mastitis caused by Streptococcus.

To further demonstrate the function of $C D 46-T V$ in bovine mastitis, RT-qPCR demonstrated that CD46-TV mRNA expression was significantly higher in mastitisinfected mammary tissues than in healthy tissues. Autophagy is a degradative mechanism involved in cell protection against invading pathogens. CD46 can play a primary function in the host's response to pathogens by regulating complement activation, and can also play an important role in CD46-dependent autophagy, which is induced as an innate immune mechanism and is a critical step in the early control of infection [35].

Several studies have investigated SNP associations with mastitis traits by genome-wide association studies in various cattle populations. Most of the reports highlighted the most significant SNPs and results of studies have differed. Many SNPs on different chromosomes (BTA 1, 3-6, 9-10, 13-17, 20-26 and X) have reached genome-wide significance for association with mastitis-related traits using the Illumina BovineSNP50 and BovineHD Beadchips [36-39]. Several SNPs with significant associations with clinical mastitis all lactations, somatic cell score and clinical mastitis first lactation were found on BTA16 (http://onlinelibrary.wiley.com/store/10.1111/age.12053/ asset/supinfo/age12053-sup-0003-FigS3.pdf?v=1\&s=d9349 1c11600b5589883f66687870486940dff5e), however, detailed SNP information was not provided [39]. No specific evidence revealed association signals in the vicinity of CD46 on BTA16 were identified in these studies. This suggests that there may be larger effect mutations on mastitis susceptibility than the mutation which produces the CD46-TV transcript.

Recent evidence suggests that SNPs are major contributors to the generation of alternative splice variants, which can cause serious human and cow diseases $[40,41]$. To test whether the c. $1033+2184 \mathrm{C}>\mathrm{T}$ SNP identified in this study plays an important role in dairy cow mastitis, an association analysis between genotypes and gEBVs of STMA, CEL and MACL showed that the Holsteins with the $\mathrm{CT}$ and $\mathrm{CC}$ genotypes were more resistant to mastitis because individuals with the TT genotype have a higher percentage of occurrence of clinical 
mastitis. Based on the results of the SNP causing the CD46-TV splice variant and the association analysis between genotype and gEBVs of mammary gland health traits in Chinese Holstein population, we predicted that CD46-TV protein caused by the SNP was very likely to have a significant role in bovine mastitis-resistance. This result requires further confirmation in a larger reference population.

\section{Conclusions}

We have identified a causative mutation in an exonic splice enhancer of the bovine $C D 46$ gene which causes the elimination of the CD46-TV splice variant. Bioinformatic prediction, relative expression and association analysis between genotype and mammary gland health traits suggest that the splice variant may be involved in resistance to mastitis caused by Streptococcus in dairy cows.

\section{Methods}

\section{Ethics statement}

All experiments were carried out according to the Regulations for the Administration of Affairs Concerning Experimental Animals published by the Ministry of Science and Technology, China in 2004 and approved by the Animal Care and Use Committee from the Dairy Cattle Research Center, Shandong Academy of Agricultural Sciences, Shandong, P. R. China.

\section{Animal, tissue samples and dataset}

Experiment one: Tissue samples were collected from healthy and mastitis-infected mammary glands of first lactation Chinese Holstein cows from a commercial slaughter plant in Jinan, Shandong Province, China. The cows were defined as healthy if they were without pathogen infection identified by a culture test and did not show any clinical signs (such as swelling, heat, redness, hardness or pain). Cows were diagnosed with clinical mastitis if the milk from one or more quarters of the mammary gland was abnormal in color or consistency, accompanied by heat, pain, redness, or swelling of the quarter. The mastitis-infected cows were collected following the presentation of clinical symptoms and Streptococcus identification via culture. A total of sixteen tissue samples ( 8 cases and 8 controls) were collected and quickly frozen in liquid nitrogen for DNA extraction for genotyping and RNA extraction for the identification of splice variants and characterization of the relative expression of $C D 46-T V$.

Experiment two: To determinate which allele was the ancestral and which was the mutant allele, a total of 56,682 individuals belonging to 112 Bos taurus (i.e. Angus, Holstein, Hereford, Limousin, Simmental, Luxi, etc.), or, Bos indicus (i.e., Boran, Brahman) breeds, and the buffalo (i.e., Cape buffalo), yak and bison species were used to analyze allele frequency at the SNP. Detailed information of animal samples is shown in Additional file 2: Table S1. These animals were genotyped with the Illumina BovineSNP50K Beadchip (San Diego, CA). The SNP (c. $1033+2184 \mathrm{C}>\mathrm{T}$ ) data was extracted from the BovineSNP50 data (Marker name of the SNP: Hapmap48320-BTA-40139; rs ID: 41634826).

Experiment three: A total of 230 Chinese Holstein cows, 3-5 years old, from the standardized dairy cattle farms (Shandong, China) were selected randomly for estimation of the genetic effect of the SNP on somatic cell score. All animals were participated enrolled in the Dairy Improvement Herd testing and were milked three times daily for a month for the data used in the association study. The somatic cell count of milk samples was measured by using a Fossomatic Cell Counter (Foss Electric, FOSSMATIC 5000, Denmark). The blood of animals was collected from the jugular vein and was placed in a tube with acid-citrate-dextrose anticoagulant for genomic DNA extraction using the Tianamp Genomic Extraction Kit (Tiangen, Beijing, China). DNA concentration was estimated spectrophotometrically, and was diluted to $50 \mathrm{ng} / \mathrm{mL}$. DNA samples were stored at $-20^{\circ} \mathrm{C}$ for subsequent analysis.

Experiment four: A total of 60 Chinese Holstein cows and 38 bulls that originated from various male lineages from the Shandong OX Biotechnology Ltd and with genomic estimated breeding values (gEBVs) for udder health synthesis (STMA), milk somatic cell score (CEL) and occurrence of clinical mastitis (MACL) were used to analyze the association between SNP genotypes and gEBV for STMA, CEL and MACL. The gEBV for Holstein udder traits was computed by the Animal Genetics Department of INRA (National Institute for Agronomic Research) and gEBV data were provided by Genes Diffusion (Douai Cedex, France).

\section{Cloning of the bovine CD46 gene coding region}

Total RNA was isolated using the RNAsimple total RNA Kit (Tiangen, Beijing, China) from the mammary tissues and $2 \mu \mathrm{g}$ RNA was reverse-transcribed to cDNA using RevertAid First Strand cDNA Synthesis Kit (Fermentas, Pittsburgh, PA, USA) according to the manufacturer's instructions. The specific primer pair (CD46F: $5^{\prime}$-TGGACT CAGCAAGGTCTCTG-3', CD46R: 5'-GCCATGTTGAC CTACCCCATA $-3^{\prime}$; Product size $=2005$ bp) was designed to amplify the coding region of the $C D 46$ gene according to the CD46 mRNA reference sequence (GenBank. NM_001242561.1). The reaction system for PCR amplification of the CD46 cDNA was described in a previous report [6]. Conditions for PCR were $4 \mathrm{~min}$ at $94^{\circ} \mathrm{C}$, followed by 35 cycles of $94^{\circ} \mathrm{C}$ for $30 \mathrm{~s}$, between $52^{\circ} \mathrm{C}$ and $65^{\circ} \mathrm{C}$ designed 12 temperature gradients for $30 \mathrm{~s}$, and $72^{\circ} \mathrm{C}$ for $1.4 \mathrm{~min}$, and a final $72^{\circ} \mathrm{C}$ extension for 
5 min. PCR products were purified, and cloned into the pEASY-T3 Vector (TransGen, Beijing, China).

\section{Relative quantitative analysis of $C D 46$ transcripts}

Real-time quantitative PCR (RT-qPCR) was performed to investigate the expression of the splice variant CD46$T V$ in healthy and mastitis-infected dairy cow tissues. The relative expression level of the different tissues was normalized using the housekeeping gene $\beta$-actin. The RT-qPCR primers for specific $C D 46-T V$ and $\beta$-actin were as follows: F1: 5'-GCCCACTTCTCCAACCATGA-3' (The primer sequence locates in the retained intronic seqence), R1: 5' -AAACCCTCAGCACCGTTAGG-3', Product size $=93 \mathrm{bp} ; \beta$-actinF: $5^{\prime}$-GCACAATGAAGA TCAAGATCATC-3', $\beta$-actinR: 5 '-CTAACAGTCCGC CTAGAAGCA-3'; Product size $=173 \mathrm{bp}$. The RT-qPCR reaction was performed under the following conditions: $94^{\circ} \mathrm{C}$ for $5 \mathrm{~min} ; 40$ cycles at $94^{\circ} \mathrm{C}$ for $15 \mathrm{~s} ; 60^{\circ} \mathrm{C}$ for $5 \mathrm{~s}$. The detailed RT-qPCR protocol was previously described [6].

\section{Mutation screening}

PCR primers (CD46F1: 5'-CCCGTGCAACATTCTTGT GC-3', CD46R1: 5'-TAAGTG TGCTACCCCACCCT-3') were designed from the CD46 gene sequence (NCBI Reference Sequence: NC_007314.4) to amplify the region around the retention position of the intron 8 sequence in the CD46-TV transcript to screen for potential SNP. PCR products from 16 individuals were sent to BGI (Beijing, China) for direct sequencing using an ABI 3730xl instrument.

\section{Minigene constructs}

A 1421 bp genomic segment of CD46 spanning exon 9, $914 \mathrm{bp}$ of intron 8 and $453 \mathrm{bp}$ of intron 9 flanking sequences was amplified from genomic DNA of heterozygotes and then the fragments with the wild or mutant alleles that were identified by sequencing were cloned into the exon trapping vector pSPL3 (Invitrogen, CA, USA), using specific primers linking the EcoRI and XhoI restriction enzyme sites (CD46-F2: 5'-CCGGAATTC CCCGTGCAACATTCTTGTGC-3', CCGGAATTC: EcoRI; CD46-R2: 5' -CCGCTCGAGTAAGTGTGCTACCCCAC CCT-3', CCGCTCGAG: XhoI). The ancestral and mutant type constructs were named pSPL3-W and pSPL3-M, respectively. All constructs were verified to contain the correct sequence by direct sequencing.

\section{Cell culture and transfection}

Human epithelial kidney 293 T (HEK 293 T) cells were cultured in DMEM medium containing 10\% fetal bovine serum (FBS), penicillin (100 U/L), and streptomycin $(100 \mathrm{mg} / \mathrm{L})$ at $37^{\circ} \mathrm{C}$ in a $5 \% \mathrm{CO}_{2}$ atmosphere. One day before transfection, cells were transferred to 6-well culture plate to grow to approximately $70 \%$ to $80 \%$ confluence in an antibiotic free medium. Cells were then transfected with $4 \mu \mathrm{g}$ plasmid DNA (pSPL3-W, pSPL3$\mathrm{M}$ and empty pSPL3-control each) using OPTI-MEM ${ }^{\circ} \mathrm{I}$ Medium and Lipofectamine 2000 (Invitrogen, Carlsbad, CA, USA) according to the manufacturer's instructions. Cells were harvested and total RNA was extracted after $24 \mathrm{~h}$ transfection with the RNAsimple Total RNA Kit (Tiangen, Beijing, China).

\section{Minigene expression analysis}

A total of $1 \mu \mathrm{g}$ of RNA from each of the transfected cells was reverse transcribed into cDNA using the SA2 primer (5'-ATCTCAGTGGTATTTGTGAGC-3') which is specific for the amplification of the pSPL3 vector and the RevertAid $^{\mathrm{Tn}}$ First Strand cDNA Synthesis Kit (Fermentas, Pittsburgh, PA, USA) according to the manufacturer's specifications.

The cDNA was amplified with pSPL3 vector specific primers (SD6: 5'-TCTGAGTCACCTGGACAACC-3'; SA2: 5'-ATCTCAGTGGTATTTGTGAGC-3'). The PCR amplification conditions were as follows: an initial denaturation at $94^{\circ} \mathrm{C}$ for $4 \mathrm{~min}$, followed by 30 cycles at $94^{\circ} \mathrm{C}$ for $30 \mathrm{~s}$, $58^{\circ} \mathrm{C}$ for $30 \mathrm{~s}, 72^{\circ} \mathrm{C}$ for $2 \mathrm{~min}$, and a final extension at $72^{\circ} \mathrm{C}$ for $5 \mathrm{~min}$. PCR products were analyzed by electrophoresis on a $2 \%$ agarose gel.

\section{Statistical analysis}

The association between the CD46 SNP marker genotypes and somatic cell score was analyzed by the least squares method as applied in the general linear models (GLM) procedure of SAS9.0 (SAS Institute Inc, Cary, NC, USA). The GLM was as follows:

$$
\mathrm{Y}_{i j k l m n}=\mu+\mathrm{F}_{i}+\mathrm{G}_{j}+\mathrm{S}_{k}+\mathrm{E}_{l}+\mathrm{H}_{m}+\mathrm{e}_{i j k l m n}
$$

Where $\mathrm{Y}_{i j k l m n}$ was the observed somatic cell score value; $\mu$ was the overall mean; $F_{i}$ was the fixed effect of farm; $G_{j}$ was the fixed effect of genotype; $S_{k}$ was the fixed effect of sire; $\mathrm{E}_{l}$ was the fixed effect of season; $\mathrm{H}_{m}$ was the fixed effect of parity; $\mathrm{e}_{i j k l m n}$ was the random residual effect.

The association between the genotypes and gEBV for STMA, CEL and MACL of bulls was tested using the T-test and One-way ANOVA program using the SAS 9.0 software. Values of $p<0.05$ were considered significant.

\section{Additional files}

Additional file 1: Figure S1. RT-PCR products from the CD46 gene expressed in bovine mammary tissues. Figure S2. Association between CD46 genotype and CD46-TV transcript abundance. Figure S3. Comparisons of bovine CD46-TV and other species' CD46 mRNA sequences.

Figure S4. Comparisons of bovine CD46-TV and other species' CD46 amino acid sequences.

Additional file 2: Table S1. Genetic parameters of the SNP (c. 1033 + 2184 C $>$ T) in 112 species. 


\section{Competing interests}

The authors declare that they have no competing interest.

\section{Authors' contributions}

XW, JH performed data analysis, XW, JZ, YG, Z, JH carried out the experiments and collected the samples. JZ, YG participated in data collection and experiment coordination. XW, JH conceived and designed the experiments. XW, JH wrote the manuscript. All authors read and approved the final manuscript.

\section{Acknowledgements}

We thank Professor J.F. Taylor from the Division of Animal Sciences, University of Missouri for providing SNP frequency data in different cattle breeds and his criticisms and editing of this manuscript. We also thank Mr. J Hoff from the Division of Animal Sciences, University of Missouri for polishing the manuscript. This study was supported by grants from the National Natural Science Foundation of China (31371255, 31271328 and 31000543), the Support Program of the Ministry of Science and Technology, P. R. China (2011BAD19B02 and 2011BAD19B04), the Major Project of National Transgene in China (2014ZX08007-001), and the Program of National Cow Industrial Technology System (CARS-37).

Received: 3 November 2013 Accepted: 15 July 2014 Published: 28 July 2014

\section{References}

1. Shook GE, Schutz MM: Selection on somatic cell score to improve resistance to mastitis in the United States. J Dairy Sci 1994, 77:648-658

2. Heringstad B, Klemetsdal G, Ruane J: Selection for mastitis resistance in dairy cattle: a review with focus on the situation in the Nordic countries. Livestock Product Sci 2000, 64:95-106.

3. Orengo JP, Cooper TA: Alternative splicing in disease. Adv Exp Med Biol 2007, 623:212-223

4. Tazi J, Bakkour N, Stamm S: Alternative splicing and disease. Biochim Biophys Acta 2009, 1792:14-26.

5. Hou QL, Huang JM, Ju ZH, Li QL, Li LM, Wang CF, Sun T, Wang LL, Hou MH, Hang SQ, Zhong JF: Identification of splice variants, targeted microRNAs and functional SNPs of the BOLA-DQA2 Gene in dairy cattle. DNA Cell Biol 2012, 31:739-744.

6. Wang XG, Huang JM, Zhao LH, Wang CF, Ju ZH, Li QL, Qi C, Zhang Y, Zhang Z, Zhang W, Hou MH, Yuan JD, Zhong JF: The exon 29 c.3535A > T in the alpha-2-macroglobulin gene causing aberrant splice variants is associated with mastitis in dairy cattle. Immunogenetics 2012, 64:807-816.

7. Li LM, Huang JM, Ju ZH, Li QL, Wang CF, Qi C, Zhang Y, Hou QL, Hang SQ, Zhong JF: Multiple promoters and targeted microRNAs direct the expressions of HMGB3 gene transcripts in dairy cattle. Anim Genet 2013, 44:241-250.

8. Chalmers IW, McArdle AJ, Coulson RM, Wagner MA, Schmid R, Hirai H, Hoffmann KF: Developmentally regulated expression, alternative splicing and distinct sub-groupings in members of the Schistosoma mansoni venom allergen-like (SmVAL) gene family. BMC Genomics 2008, 9:89.

9. Gilboa-Geffen A, Hartmann G, Soreq H: Stressing hematopoiesis and immunity: an acetylcholinesterase window into nervous and immune system interactions. Front Mol Neurosci 2012, 5:30.

10. Eizirik DL, Sammeth M, Bouckenooghe T, Bottu G, Sisino G, Igoillo-Esteve M, Ortis F, Santin I, Colli ML, Barthson J, Bouwens L, Hughes L, Gregory L, Lunter G, Marselli L, Marchetti P, McCarthy MI, Cnop M: The human pancreatic islet transcriptome: expression of candidate genes for type 1 diabetes and the impact of pro-inflammatory cytokines. PLOS Genet 2012, 8:e1002552.

11. Cáceres JF, Kornblihtt AR: Alternative splicing: multiple control mechanisms and involvement in human disease. Trends Genet 2002, 18:186-193.

12. Wahl MC, Will CL, Lührmann R: The spliceosome: design principles of a dynamic RNP machine. Cell 2009, 136:701-718.

13. Graveley BR: Sorting out the complexity of SR protein functions. RNA 2000, 6:1197-1211.

14. Blencowe BJ: Exonic splicing enhancers: mechanism of action, diversity and role in human genetic diseases. Trends Biochem. Sci 2000, 25:106-110.

15. Sterne-Weiler T, Howard J, Mort M, Cooper DN, Sanford JR: Loss of exon identity is a common mechanism of human inherited disease. Genome Res 2011, 21:1563-1571.
16. Weisschuh N, Wissinger B, Gramer E: A splice site mutation in the PAX6 gene which induces exon skipping causes autosomal dominant inherited aniridia. Mol Vis 2012, 18:751-777.

17. Cattaneo R, Hawkins ED, Oliaro J: Four viruses, two bacteria, and one receptor: membrane cofactor protein (CD46) as pathogens' magnet. J Virol 2004, 78:4385-4388.

18. Zezafoun H, Decreux A, Desmecht D: Genetic and splice variations of Bos taurus CD46 shift cell permissivity to BVDV, the bovine pestivirus. Vet Microbiol 2011, 152:315-327.

19. Liszewski MK, Post TW, Atkinson JP: Membrane cofactor protein (MCP or CD46): newest member of the regulators of complement activation gene cluster. Annu Rev Immunol 1991, 9:431-455.

20. Barilla-LaBarca ML, Liszewski MK, Lambris JD, Hourcade D, Atkinson JP: Role of membrane cofactor protein (CD46) in regulation of $\mathrm{C} 4 \mathrm{~b}$ and $\mathrm{C} 3 \mathrm{~b}$ deposited on cells. J Immunol 2002, 168:6298-6304.

21. Kemper C, Chan AC, Green JM, Brett KA, Murphy KM, Atkinson JP: Activation of human CD4+ cells with CD3 and CD46 induces a T-regulatory cell 1 phenotype. Nature 2003, 421:388-392.

22. Cardone J, Le Friec G, Vantourout $P$, Roberts A, Fuchs A, Jackson I, Suddason T, Lord G, Atkinson JP, Cope A, Hayday A, Kemper C: Complement regulator CD46 temporally regulates cytokine production by conventional and unconventional T cells. Nat Immuno/ 2010, 11:862-871.

23. Hawkins ED, Oliaro J: CD46 signaling in T cells: linking pathogens with polarity. FEBS Lett 2010, 584:4838-4844.

24. Joubert PE, Meiffren G, Grégoire IP, Pontini G, Richetta C, Flacher M, Azocar O, Vidalain PO, Vidal M, Lotteau V, Codogno P, Rabourdin-Combe C, Faure M: Autophagy induction by the pathogen receptor CD46. Cell Host Microbe 2009, 6:354-366

25. Cartegni L, Wang J, Zhu Z, Zhang MQ, Krainer AR: ESEfinder: a web resource to identify exonic splicing enhancers. Nucleic Acids Res 2003, 31:3568-3571.

26. Crick F: Split gene and RNA splicing. Science 1979, 204:264-271.

27. Koivula M, Mäntysaari EA, Negussie E, Serenius T: Genetic and phenotypic relationships among milk yield and somatic cell count before and after clinical mastitis. J Dairy Sci 2005, 88:827-833.

28. Huang JM, Wang HM, Wang CF, Li JB, Li QL, Hou MH, Zhong JF: Single nucleotide polymorphisms, haplotypes and combined genotypes of lactoferrin gene and their associations with mastitis in Chinese Holstein cattle. Mol Biol Rep 2010, 37:477-483.

29. Gabut M, Miné M, Marsac C, Brivet M, Tazi J, Soret J: The SR protein SC35 is responsible for aberrant splicing of the E1alpha pyruvate dehydrogenase mRNA in a case of mental retardation with lactic acidosis. Mol Cell Biol 2005, 25:3286-3294.

30. Huang CS, Shen CY, Wang HW, Wu PE, Cheng CW: Increased expression of SRp40 affecting CD44 splicing is associated with the clinical outcome of lymph node metastasis in human breast cancer. Clin Chim Acta 2007, 384:69-74.

31. Iwata K, Seya T, Yanagi Y, Pesando JM, Johnson PM, Okabe M, Ueda S, Ariga $H$, Nagasawa S: Diversity of sites for measles virus binding and for inactivation of complement $\mathrm{C} 3 \mathrm{~b}$ and $\mathrm{C} 4 \mathrm{~b}$ on membrane cofactor protein CD46. J Biol Chem 1995, 270:15148-15152.

32. Källström H, Liszewski MK, Atkinson JP, Jonsson AB: Membrane cofactor protein (MCP or CD46) is a cellular pilus receptor for pathogenic Neisseria. Mol Microbiol 1997, 25:639-647.

33. Källström H, Blackmer Gill D, Albiger B, Liszewski MK, Atkinson JP, Jonsson AB: Attachment of Neisseria gonorrhoeae to the cellular pilus receptor CD46: identification of domains important for bacterial adherence. Cell Microbiol 2001, 3:133-143.

34. Feito MJ, Sánchez A, Oliver MA, Pérez-Caballero D, de Córdoba Rodríguez S, Albertí S, Rojo JM: Membrane cofactor protein (MCP, CD46) binding to clinical isolates of Streptococcus pyogenes: binding to M type 18 strains is independent of Emm or Enn proteins. Mol Immunol 2007, 44:3571-3579.

35. Meiffren G, Joubert PE, Grégoire IP, Codogno P, Rabourdin-Combe C, Faure M: Pathogen recognition by the cell surface receptor CD46 induces autophagy. Autophagy 2010, 6:299-300.

36. Minozzi G, Nicolazzi EL, Strozzi F, Stella A, Negrini R, Ajmone-Marsan P, Williams JL: Genome wide scan for somatic cell counts in Holstein bulls. BMC Proc 2011, 5(Suppl 4):S17.

37. Meredith BK, Kearney FJ, Finlay EK, Bradley DG, Fahey AG, Berry DP, Lynn DJ: Genome-wide associations for milk production and somatic cell score in Holstein-Friesian cattle in Ireland. BMC Genet 2012, 13:21. 
38. Meredith BK, Berry DP, Kearney F, Finlay EK, Fahey AG, Bradley DG, Lynn DJ: A genome-wide association study for somatic cell score using the Illumina high-density bovine beadchip identifies several novel QTL potentially related to mastitis susceptibility. Front Genet 2013, 4:229.

39. Sahana G, Guldbrandtsen B, Thomsen B, Lund MS: Confirmation and fine-mapping of clinical mastitis and somatic cell score QTL in Nordic Holstein cattle. Anim Genet 2013, 44:620-626.

40. Drögemüller $C$, Reichart U, Seuberlich T, Oevermann A, Baumgartner M, Kühni Boghenbor K, Stoffel MH, Syring C, Meylan M, Müller S, Müller M, Gredler B, Sölkner J, Leeb T: An unusual splice defect in the mitofusin 2 gene (MFN2) is associated with degenerative axonopathy in Tyrolean Grey cattle. PLoS One 2011, 6:e18931.

41. Menoud A, Welle M, Tetens J, Lichtner P, Drögemüller C: A COL7A1 mutation causes dystrophic epidermolysis bullosa in Rotes Höhenvieh cattle. PLoS One 2012, 7:e38823.

doi:10.1186/1471-2164-15-630

Cite this article as: Wang et al: A SNP in intron 8 of CD46 causes a novel transcript associated with mastitis in Holsteins. BMC Genomics 2014 15:630.

\section{Submit your next manuscript to BioMed Central and take full advantage of:}

- Convenient online submission

- Thorough peer review

- No space constraints or color figure charges

- Immediate publication on acceptance

- Inclusion in PubMed, CAS, Scopus and Google Scholar

- Research which is freely available for redistribution 